\title{
CFD-Based Determination of the Optimal Blowing and Suction Air Volume Ratio of Dual-Radial Swirl Shielding Ventilation in a Fully Mechanized Excavation Face
}

\author{
Kuan Wu $\mathbb{D}^{1,2}$ Shiliang Shi $\mathbb{D}^{1,2}$ Yijie Shi $\mathbb{D}^{1,2}$ and Yong Chen $\mathbb{D}^{1,3,4}$ \\ ${ }^{1}$ School of Resource \& Environment and Safety Engineering, Hunan University of Science and Technology, Xiangtan, China \\ ${ }^{2}$ Hunan University of Science and Technology Southern Coal Mine Gas and Roof Disaster Prevention and Control and Safety \\ Production Key Experiment, China \\ ${ }^{3}$ China Coal Technology Engineering Group Chongqing Research Institute, Chongqing 400037, China \\ ${ }^{4}$ National Key Laboratory of Gas Disaster Detecting, Preventing and Emergency Controlling, Chongqing 400037, China
}

Correspondence should be addressed to Kuan Wu; 170101020001@mail.hnust.edu.cn

Received 21 June 2021; Accepted 21 August 2021; Published 17 September 2021

Academic Editor: Bo Tan

Copyright (C) 2021 Kuan Wu et al. This is an open access article distributed under the Creative Commons Attribution License, which permits unrestricted use, distribution, and reproduction in any medium, provided the original work is properly cited.

\begin{abstract}
Dust is one of the main pollutants in coal mines, which seriously affects the physical and mental health of workers, as well as the safe production in underground mines. Dual-radial swirl shielding ventilation is a new ventilation method for a fully mechanized excavation face and can effectively reduce the dust concentration in the underground. The dust control effect of dual-radial swirl shielding ventilation is mainly affected by the thickness and integrity of the shielding air curtain, as well as the disturbance of the flow field near the air curtain. By changing the blowing and suction air volume ratio of the air duct, the strength of the radial air curtain can be improved, and the dust control effect of the dual-radial swirl shielding ventilation system can be effectively improved. In order to determine the optimal operating parameters of the dual-radial swirl shielding ventilation system, a numerical simulation method was used to conduct an in-depth study on the blowing and suction air volume ratio of the system. The results showed that when the blowing and suction air volume ratio of the air duct was 1.5 , the radial air curtain had the highest strength. Under this condition, the dust concentration at the driver's position of the roadheader was the lowest, and the dual-radial swirl shielding ventilation system can achieve an ideal dust control effect.
\end{abstract}

\section{Introduction}

Coal resources are an important energy mineral resource. China's total coal consumption accounts for about $60 \%$ of the country's total energy consumption [1,2]. With the increasing level of intelligence, mechanization, and automation of mines, potential hazards such as gas, coal dust, and fires have increased, especially dust pollution of mines, which seriously affects the safety of enterprises and the occupational health of workers [3-5]. In 2019, China reported 19,428 new cases of various occupational diseases, of which 15,898 were occupational pneumoconiosis, accounting for $81.8 \%$ of the new cases of various occupational diseases [6-8]. The direct economic loss caused by pneumoconiosis in China is more than 8 billion RMB per year, and the indirect loss is even more difficult to calculate. There is still a lot of room for improvement in the development of dust control theory and technology $[9,10]$.

The fully mechanized excavation face has the most serious dust hazard in underground coal mines [11-13]. At present, the fully mechanized excavation face mainly uses coal seam water injection, spraying, and ventilation to reduce the dust concentration. Due to the characteristics of large dust production and small dust particle size in the fully mechanized excavation face, compared with other dust removal technologies, ventilation and dust control are the most convenient and efficient technology to reduce the concentration of dust in the fully mechanized excavation face without affecting the working environment in the roadway [14-16]. The ventilation and dust control technology of the fully mechanized 
excavation face are to control the dust within a certain area around the fully mechanized excavation face by regulating the airflow field and to prevent the spread of dust from the excavation face $[17,18]$. Currently, coal mines in China and other countries mainly adopt long-pressure and shortextraction ventilation to dilute the excavated dust and suck the dust-containing airflow into the dust collector for purification $[19,20]$. However, since the use of circulating air is prohibited, the traditional long-pressure and short-exhaust ventilation requires the air supply volume to be greater than the suction air volume, so the dust-containing gas at the tunneling end cannot be exhausted by the suction tube. As a result, the dust is widespread in the roadway under the action of the air supply flow [21-24]. In order to prevent the largescale spread of dust in the roadway, former West Germany first developed a wall-attached air duct. A wall-attached duct is a duct with an air outlet on the side of the air supply duct to improve the distribution of the airflow field in the fully mechanized excavation face. The airflow from the side air outlet forms a shielding air curtain on the roadway to prevent the spread of dust and improve the dust-catching effect of the air inlet. The wall-attached air duct can greatly improve the working environment of the fully mechanized excavation face, prevent gas accumulation on the top of the roadway, and ensure the safe production of the mine [25, 26]. However, the radial air curtain produced by the wallattached air duct has a relatively weak rotation ability, and it is very easy to form a hollow air curtain due to the serious impact of the roadway environment. As a result, the dustblocking ability is insufficient $[27,28]$.

In order to solve the problems of high dust concentration and turbulent air organization in the fully mechanized excavation face, the wall-attached swirl ventilation system was improved to form a new type of ventilation system for the fully mechanized excavation face, i.e., the dual-radial swirl shielding ventilation system. In this study, by taking the fully mechanized excavation face of a coal mine in northern China as the research object, a new dual-radial swirl shielding ventilation system for the fully mechanized face was designed. A simulated tunnel model was built to scale, and the airflow field structure and dust movement rules in the roadway under the dual-radial swirl shielding ventilation system were studied using Fluent software, especially the dust concentration in the working area of the roadheader driver. The validity of the numerical simulation was verified through a custom-built roadway model experiment platform. Finally, numerical simulations were used to study the dust control effect of the dual-radial swirl shielding ventilation system under different air duct blowing and suction volume ratios, and the working condition parameters for the best dust control were obtained.

\section{Principle of Dual-Radial Swirl Shielding Ventilation and Dust Control}

Dual-radial swirl shielding ventilation is a new ventilation method for a fully mechanized excavation face. Its working principle is somewhat similar to that of wall swirling ventilation; that is, a radial air curtain is formed on the section of the roadway to block the spread of dust. Compared with the radial air curtain formed by the wall swirling ventilation, the radial air curtain formed by the dual-radial swirl shielding ventilation has a higher strength. It is because in the dual-radial swirl shielding ventilation, the formed rotating air curtain on the fully mechanized excavation face is produced by an arc-shaped wind deflector. Compared with the rotating air curtain produced by the attachment of the roadway, the shielding air curtain formed by the dual-radial swirl shielding ventilation system has a larger radial wind speed, evener distribution, and a larger thickness. Therefore, the dual-radial swirl ventilation has a better effect in preventing the spread of dust.

During the excavation, the dust concentration in the roadway is extremely high. Turn on the dust removal fan and the blower, adjust the air valve, and deliver all the airflow to the air pressure sleeve; then, the air is discharged radially from the air curtain generator device at both ends of the sleeve. Under the action of the air curtain generating device, a rotating radial solid air curtain is formed between the tunneling end and the driver's cab of the roadheader, and another radial air curtain is formed between the driver's $\mathrm{cab}$ and the transfer point. Under the negative pressure of the suction port, the $1 \#$ air curtain near the tunneling end forms an umbrella-shaped swirling air curtain that rushes toward the tunneling end to control the dust produced by the tunneling within a small area. The controlled dust is drawn out by the suction tube to prevent the dust from spreading to the driver's cab, thus providing a good working environment for the driver. The $2 \#$ air curtain located in front of the transfer point isolates the dust at the transfer point from the driver's position, thus preventing dust from spreading from the transfer point to the driver's position. The synergistic action of the two air curtains can effectively isolate the two main dust sources of the fully mechanized excavation face from the area of the driver of roadheader, providing a good working environment for the driver. Figure 1 shows a schematic diagram of dual-radial swirl shielding ventilation on the fully mechanized excavation face when the roadheader works normally.

\section{Calculation Model and Validation}

3.1. Calculation Model and Meshing. By taking the fully mechanized excavation face of a coal mine in China as a prototype, a numerical simulation geometric model with a ratio of 1:1 was established by Solidworks software. The fully mechanized excavation face is a semicircular arched roadway with a cross-section of $4.6 \mathrm{~m} \times 4.5 \mathrm{~m}$ and a crosssectional area of $15.81 \mathrm{~m}^{2}$. The fully mechanized excavation face is tunneled with an EBZ160 roadheader. Figure 2 shows the diagram of the roadway model. From the figure, the air supply tube I has a diameter of $0.8 \mathrm{~m}$ and a tube length of $25 \mathrm{~m}$. It is attached to a sidewall of the roadway. Its axis is $2.7 \mathrm{~m}$ away from the ground of the roadway, and the air outlet at the end is $5 \mathrm{~m}$ away from the excavation face. The sleeve is composed of air supply tube II and the air suction tube. The air supply tube II is outside, and the suction tube is inside. The center axis of the sleeve is $2.7 \mathrm{~m}$ from the 


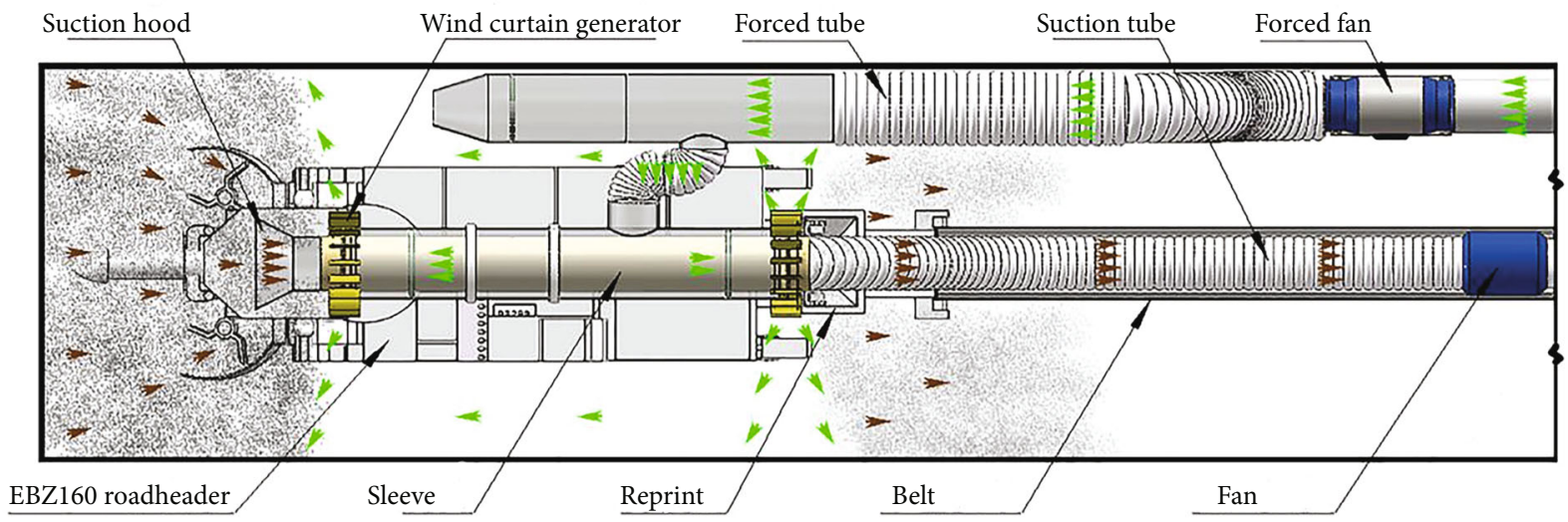

FIgURE 1: Schematic diagram of dual-radial swirl shielding ventilation.

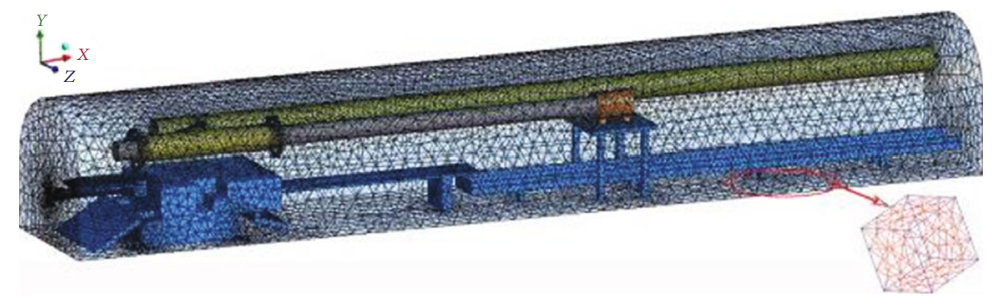

Figure 2: Schematic diagram of meshing.

ground of the roadway. There is an annular slit with a width of $0.09 \mathrm{~m}$ at each end of the air supply cylinder II, and an air curtain-generating device is arranged outside the annular slit. The diameter of the suction tube is $0.6 \mathrm{~m}$, and its suction outlet at the end is $2.3 \mathrm{~m}$ away from the excavation face. A $1.8 \mathrm{~m}$ high roadheader, a first conveyor, and a second conveyor are arranged under the sleeve. The driver is $5 \mathrm{~m}$ from the excavation face.

Mesh software was used to mesh the built roadway model. Because the geometric model was relatively complex, the model was meshed with an adaptable unstructured grid and the global grid size was set to $0.4 \mathrm{~mm}$. For arc-shaped wind deflectors and annular slits, $0.01 \mathrm{~m}$ grids were used for local densification. For other more complex structures, $0.05 \mathrm{~m}$ grids were used for local densification. A total of 932,351 grids were generated.

3.2. Mathematical Model. Since the volume fraction of dust in the fully mechanized excavation face was far below $10 \%$, when using Fluent software to analyze the characteristics of the wind flow field and dust distribution, the $k-\varepsilon$ double equation model from the Euler model was used to establish the mathematical model of the wind flow field in the fully mechanized excavation face. In addition, according to the characteristics of the gas-dust particle two-phase flow and the theory of the gas-solid two-phase flow, the Euler-Euler model and the Euler-Lagrangian model were combined for calculation.

3.2.1. Hydrodynamic Equation. Based on the law of conservation of energy, the law of conservation of momentum, and the law of conservation of mass, the characteristics of fluid motion are expressed in terms of continuity equation, momentum equation, and energy equation [29, 30].

Continuity equation:

$$
\frac{\partial \rho}{\partial t}+\frac{\partial}{\partial x_{i}}\left(\rho u_{i}\right)=S_{m}
$$

Momentum equation:

$$
\frac{\partial}{\partial t}\left(\rho u_{i}\right)+\frac{\partial}{\partial x_{j}}\left(\rho u_{i} u_{j}\right)=-\frac{\partial p}{\partial x_{i}}+\frac{\partial \tau_{i j}}{\partial x_{j}}+\rho g_{i}+F_{i}
$$

Energy equation:

$\frac{\partial}{\partial t}(\rho E)+\frac{\partial}{\partial x_{i}}\left(u_{i}(\rho E+p)\right)=\frac{\partial}{\partial x_{i}}\left(k_{\text {eff }} \frac{\partial T}{\partial x_{i}}-\sum_{j^{\prime}} h_{j^{\prime}} J_{j^{\prime}}+u_{j}\left(\tau_{i j}\right)_{\text {eff }}\right)+S_{h}$,

where $S_{m}$ is the mass added to the continuous phase from the dispersed secondary phase; $p$ is the static pressure; $\tau_{i j}$ is the stress tensor that will be described below; $\rho_{g i}$ and $F_{i}$ are the gravitational volume force and external volume force in $i$ direction, respectively; $k_{\text {eff }}$ is the effective heat transfer coefficient; $J_{j}{ }^{\prime}$ is the diffusion flow of component $j$; and $S_{h}$ includes the heat of chemical reaction and the volume heat source term.

3.2.2. Turbulence Equation. Turbulence occurs where the velocity changes. Compared with the standard $k-\varepsilon$ model, the realizable $k-\varepsilon$ model can accurately predict the divergence ratio of the cylindrical jet and it has been used to 
describe uniform shear flow with the rotating, free flow of the mixed flow and boundary layer flow effectively. And the realizable $k-\varepsilon$ model in the turbulence model can achieve a higher degree of simulation in terms of the vortex, strong streamline bending, and rotation. In addition, among many $k$ - $\varepsilon$ models, the realizable $k-\varepsilon$ model has a good effect on the complicated secondary flow and separation flow. The realizable $k-\varepsilon$ model consists of a $k$ equation (turbulent energy equation) and an $\varepsilon$ equation (turbulent energy dissipation rate equation) $[31,32]$. Therefore, this study selected realizable $k-\varepsilon$ for describing airflow motion.

$\kappa$ equation:

$$
\frac{\partial(\rho k)}{\partial t}+\frac{\partial\left(\rho k u_{i}\right)}{\partial x_{i}}=\frac{\partial}{\partial x_{j}}\left[\left(\mu+\frac{\mu_{t}}{\sigma_{k}}\right) \frac{\partial k}{\partial x_{j}}\right]+G_{k}-\rho \varepsilon
$$

$\varepsilon$ equation:

$$
\frac{\partial(\rho \varepsilon)}{\partial t}+\frac{\partial\left(\rho \varepsilon u_{i}\right)}{\partial x_{i}}=\frac{\partial}{\partial x_{j}}\left[\left(\mu+\frac{\mu_{t}}{\sigma_{\varepsilon}}\right) \frac{\partial \varepsilon}{\partial x_{j}}\right]+\rho C_{1} E \varepsilon-\rho C_{2} \frac{\varepsilon^{2}}{k+\sqrt{v \varepsilon}} .
$$

In the formulas, $\mu_{t}$ is the eddy viscosity coefficient; $\sigma_{k}$ and $\sigma \varepsilon$ are the Prandtl coefficients corresponding to $k$ and $\varepsilon$, respectively; $G_{k}$ is the turbulent flow energy generation term caused by the average velocity gradient; $C_{1}$ and $C_{2}$ are constants; $u$ is the fluid velocity; and $J_{i}$ is the material diffusion flux produced by the concentration gradient.

3.2.3. Equations of Motion for Particles. ANSYS Fluent predicts the trajectory of a discrete phase particle (or droplet or bubble) by integrating the force balance on the particle, which is written in a Lagrangian reference frame. This force balance equates the particle inertia with the forces acting on the particle and can be written as

$$
\mathrm{m}_{p} \frac{d \overrightarrow{u_{p}}}{d t}=m_{p} \frac{\vec{u}-\vec{u}_{p}}{\tau_{r}}+m_{p} \frac{\vec{g}\left(\rho_{p}-\rho\right)}{\rho_{p}}+\vec{F}
$$

where $m_{p}$ is the particle mass, $\vec{u}$ is the fluid phase velocity, $\overrightarrow{u_{p}}$ is the particle velocity, $\rho$ is the fluid density, $\rho_{p}$ is the density of the particle, $\vec{F}$ is an additional force, $m_{p}\left(\left(\vec{u}-\vec{u}_{p}\right) / \tau_{r}\right)$ is the drag force, and $\tau_{r}$ is the droplet or particle relaxation time calculated by

$$
\tau_{r}=\frac{\rho_{p} d_{p}^{2}}{18 \mu} \frac{24}{C_{d} \operatorname{Re}}
$$

where $\mu$ is the molecular viscosity of the fluid, $d_{p}$ is the particle diameter, and $\mathrm{Re}$ is the relative Reynolds number, which is defined as

$$
\operatorname{Re}=\frac{\rho d\left|\overrightarrow{u_{p}}-\vec{u}\right|}{\mu}
$$

3.3. Model Validation. In order to verify the validity of the numerical simulation model of dual-radial swirl shielding ventilation, similar experiments were carried out on the dual-radial swirl shielding ventilation system of a fully mechanized excavation face. A custom-developed dualradial swirl shielding ventilation experiment system for a fully mechanized excavation face was used to record the airflow field structure and dust concentration distribution in the roadway under the dual-radial swirl shielding ventilation, and the experimental results were compared with the numerical simulation results.

3.3.1. Experimental System and Equipment. This verification experiment used a custom-designed experimental model and a custom-built experimental platform. The roadway model was built according to the actual roadway of a coal mine in China at the ratio of $1: 10$. The main body of the semicircular arched roadway was assembled by three pieces of transparent plexiglass. The total length of the roadway was $3.00 \mathrm{~m}$, the width was $0.46 \mathrm{~m}$, the height was $0.45 \mathrm{~m}$, and the cross-sectional area was $0.16 \mathrm{~m}^{2}$. There were $10 \mathrm{~cm}$ round holes on the end surface of the roadway and one sidewall, which can be connected with the dust generator to simulate the dust production of tunneling and the dust emission at the transfer point, respectively. The interior of the tunnel was equipped with air supply ducts, suction ducts, blowers, dust removal fans, simulated roadheaders, and simulated conveyors. The layout of the experimental model is shown in Figure 3.

In the flow field analysis experiment, the PIV particle image velocity measurement system produced by LaVision, Germany, was used to record the flow field of different sections in the roadway model. The flow situation and the spatial distribution of the flow field were obtained. In the dust similarity verification experiment, the German AG420 aerosol generator was used to generate dusts, and compressed air was used as the driving force to transport the dust from the tunneling end and the round holes on the sidewall of the tunnel to the tunnel model to simulate dust production in the tunnel and dust emission at the transfer point. An FCC-25 explosion-proof dust sampler was used for dust sampling to measure the dust concentration at the measurement points.

3.3.2. Experimental Program. The verification experiment tested the flow field and the dust control effect. In the flow field verification experiment, smoke particles with a sufficiently small and uniform particle size were used as tracer particles. The smoke was transported to the study area through a blower. When the flow field was stable, the flow field of the studied roadway section was recorded using a PIV system. The velocity vector diagram of the tunnel section obtained by the experiment was compared with the numerical simulation for verification. In the dust control effect verification experiment, the dust collected by the dust sampler at different measurement points was weighed, and the dust concentration at different measurement points under different working conditions was calculated according to the sampling time and sampling flow rate set by the sampler. 


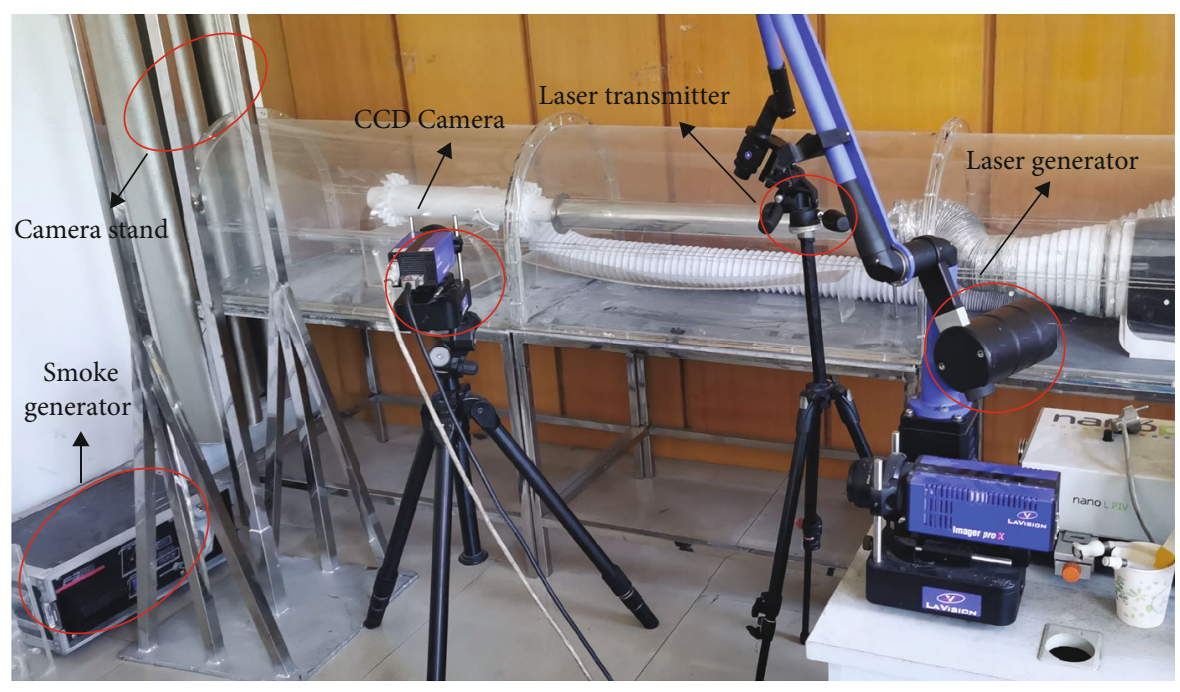

FIGURE 3: Experimental model of the fully mechanized excavation face.

Based on the dust concentration at different points, the dust control capability of the dual-radial swirl shielding ventilation system was investigated. The dust concentration distribution obtained from the experiment was compared with the numerical simulation to verify the validity of the simulation.

We selected three representative flow field measurement surfaces that were not disturbed by the model and used the PIV system to record the flow field. The 1\# measurement surface was in parallel with the tunneling end face and $5 \mathrm{~cm}$ away from the tunneling end face, the $2 \#$ measurement surface was perpendicular to the tunneling end face and the ground and passed through the center of the sleeve, and the 3\# measurement surface was in parallel with the ground and passed through the center of the sleeve. The three dust sampling points were arranged in the model roadway along the length of the roadway ( $x$-axis), i.e., at the tunneling end (point $\mathrm{A}, x=3 \mathrm{~cm}$ ), at the roadheader's cab (point $\mathrm{B}, x=$ $50 \mathrm{~cm}$ ), and the transfer point (point $\mathrm{C}, x=100 \mathrm{~cm}$ ). The flow field measurement surfaces and the arrangement of dust sampling points are shown in Figure 4.

3.3.3. Experimental Results and Analysis. Figures 5(a)-5(c) show the PIV experimental record results of the flow field test in the surfaces of $1 \#, 2 \#$, and 3\#, respectively, and Figures 5(d)-5(f) are the corresponding simulation results. Comparing Figure 5(a) with Figure 5(d), Figure 5(b) with Figure 5(e), Figure 5(c) with Figure 5(f), it can be found that the numerically calculated wind flow field structure is consistent with the PIV results. Due to limited experimental conditions, the appearance of the roadheader in the experiment was much simpler than that in the numerical simulation modeling. Compared with the internal flow in the roadway model in the simulation, the airflow field in the experiments was more idealized. Thus, the wind velocity in similar experiments was slightly larger than the numerical simulation results.

Figure 6 shows the dust concentration at different measurement points under the same working condition by experiment and numerical simulation. From the experimen- tal data in the figure, among the three measurement points, point A (the tunneling end area) has the highest dust concentration and point B (the roadheader driver's cab) has the lowest dust concentration. Under the action of the dualradial swirl shielding ventilation and dust control system in the fully mechanized excavation face, the tunneling dust was controlled within the tunneling end area, and the dust at the transfer point was also shielded in the area outside the driver's cab. Therefore, the radial air curtain can effectively prevent the spread of dust from various dust sources.

Based on the comprehensive comparison of similar experiments and numerical simulation results, we revealed that the approximate numerical results had the same trend as the experimental results. Therefore, the relevant mathematical model established in this study can be used in the numerical simulation research of the wind flow field in a fully mechanized excavation face. Since the similar experimental roadway model was built at a scale of $1 / 10$ of the actual roadway, the volume of the dust sampler in the roadway model was relatively large, and the dust sampler had a large interference to the airflow field inside the roadway model, destroying the airflow field structure and reducing the dust control effect of the ventilation system. Thus, the dust concentration at each measurement point measured by similar experiments was higher than the numerical simulation result. Comparing the results of similar experiments and numerical simulations, it can be found that although the dust concentrations obtained by similar experiments and numerical simulations were different in numerical values, the dust concentration distribution patterns were the same.

\section{Analysis of Dust Control Effect and Parameter Optimization of Dual-Radial Swirl Shielding Ventilation}

The blowing and suction air volume ratio $\gamma$ of the air duct plays a decisive role in the overall movement direction of the airflow in the tunnel. When the value of $\gamma$ is less than 

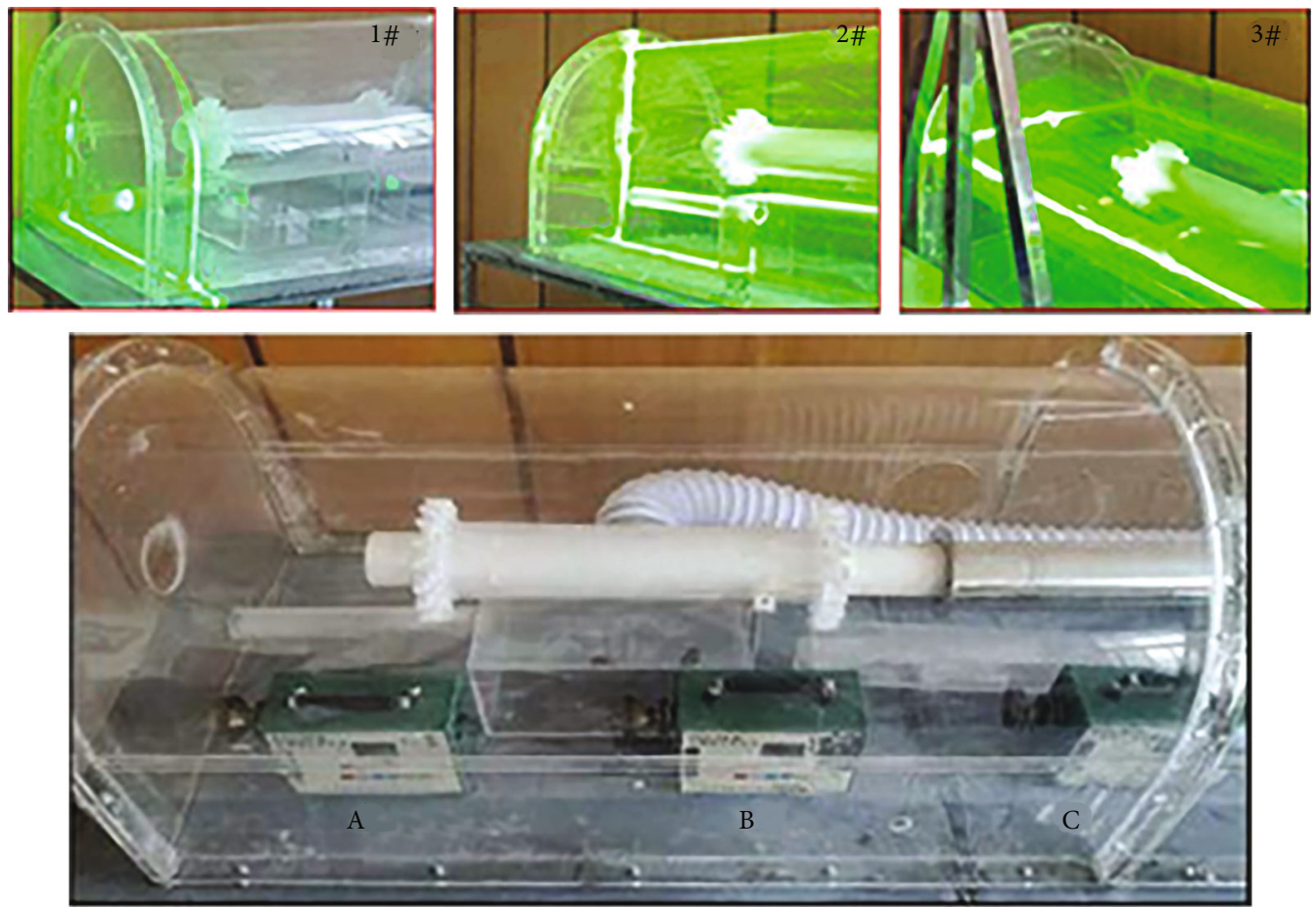

FIGURE 4: PIV measurement surfaces and dust sampling points.

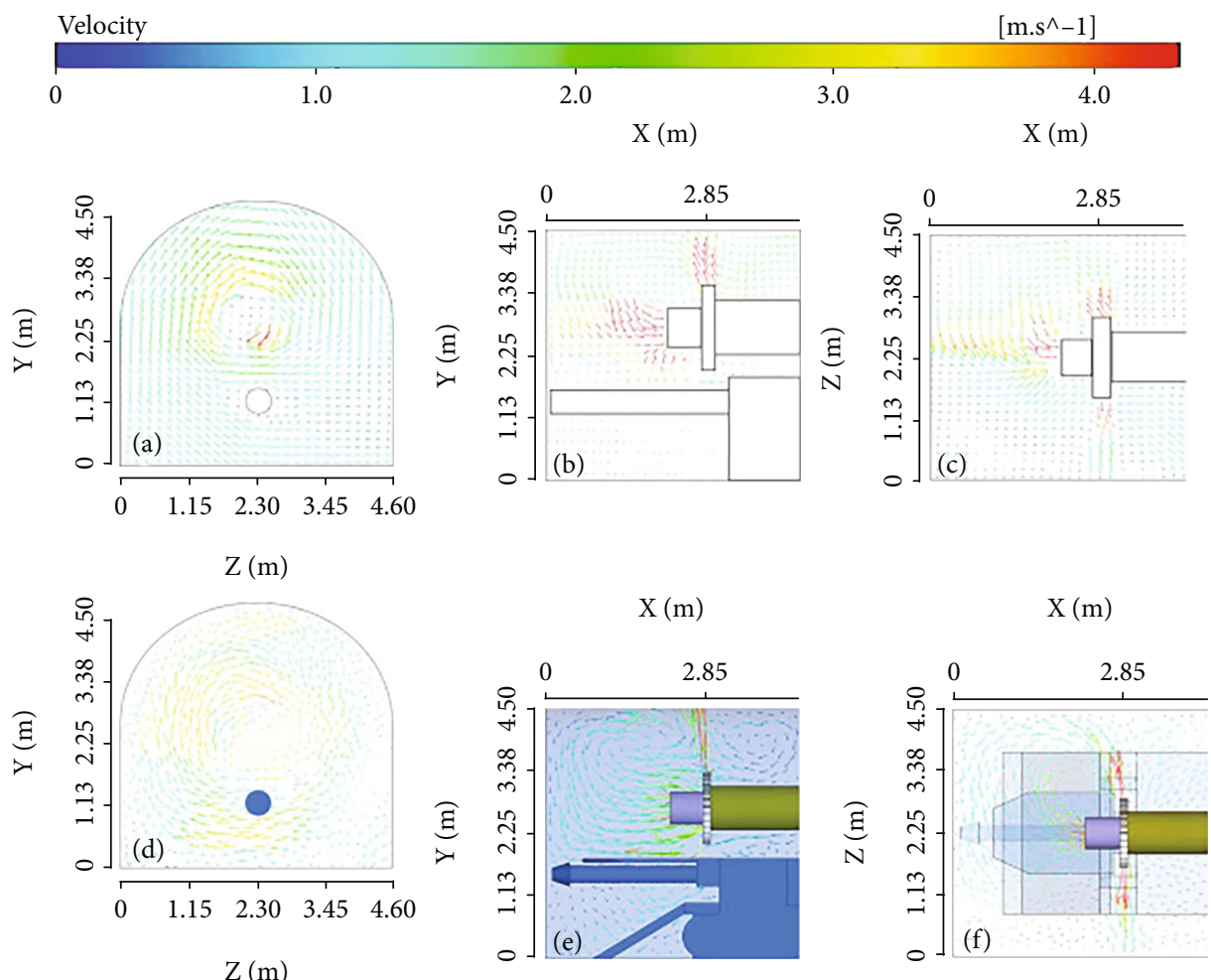

Figure 5: Comparison of experimental and numerical simulation flow fields.

1 , the airflow in the roadway moves towards the suction outlet of the suction tube, and the dust at the transfer point will spread to the driver's cab of the roadheader with the $2 \#$ air curtain. When the value of $\gamma$ is large, the tunneling dust spreads to the driver's cab of the roadheader with part of the wind flow of the $1 \#$ air curtain, and the insufficient negative pressure at the suction outlet seriously reduces the dust collection efficiency of the suction tube, resulting 


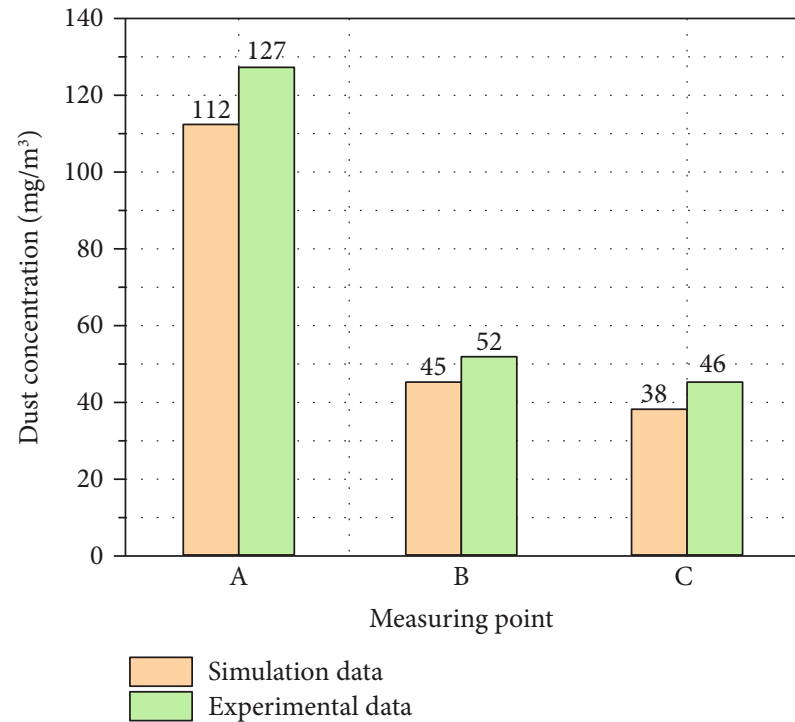

FIGURE 6: Comparison chart of different measurement points under the same working condition.

in an increase in the burden of the $1 \#$ air curtain and a decrease in the shielding effect of the tunneling dust. Therefore, a too small or too large $\gamma$ value is not conducive to the dust shielding of the air curtain on the fully mechanized excavation face.

4.1. Parameter Settings. In order to investigate the influence of the air duct blowing and suction volume ratio $\gamma$ on the effect of dual-radial swirl shielding ventilation and dust control, this simulation sets a total of six air duct blowing and suction volume ratios, i.e., 1.2, 1.3, 1.4, 1.5, 1.6, and 1.7. According to the relevant specifications of the air volume in the mine tunnel and on-site measured data, the blowing volume of the air supply tube was set to 300 $\mathrm{m}^{3} / \mathrm{min}$, and the air suction volume of the suction tube was calculated by the air tube blowing and suction volume ratio $\gamma$. The specific parameters are shown in Table 1.

4.2. Effect of the Blowing and Suction Air Volume Ratio on the Flow Field. Figure 7 shows the speed vector diagram of the section at $Z=2.3 \mathrm{~m}$ perpendicular to the tunneling end under different air duct blowing and suction air volume ratios. It can be seen from the figure that a too small or too large air duct blowing and suction ratio $\gamma$ is not conducive to shielding the dusts within the tunnel section by the radial air curtain.

For the 1\# air curtain, when the $\gamma$ value was small, the suction volume of the suction tube was relatively large, and the $1 \#$ air curtain close to the air inlet was affected by the large negative pressure at the suction outlet, and the airflow from the 1 \# slit was caught by the suction tube before reaching the roadway. As a result, the 1 \# air curtain was unable to completely block the tunnel section, which was not conducive to dust control. As the value of $\gamma$ gradually increased, the suction volume of the suction tube gradually decreased, the negative pressure generated at the suction outlet also gradually decreased, the airflow gradually reached the road- way wall, and the 1 \# air curtain moved toward the tunneling end face in an umbrella shape to completely block the roadway. When the $\gamma$ value was 1.5 , the airflow from the 1 \# slit was blown to the roadway wall at a certain angle under the action of negative pressure, moved along the tunneling end face of the roadway wall, and finally flowed to the air suction outlet under the action of the negative pressure at the air suction outlet. Under this condition, the $1 \#$ air curtain achieved a complete wrapping effect in the tunneling end area, and the best flow field in the tunneling end area was achieved. When the $\gamma$ value was too large, the suction volume of the suction tube was small, and it was difficult for the negative pressure generated by the suction outlet to affect the high-speed airflow from the 1 \# slit. The highspeed airflow blew vertically to the roadway wall, causing strong wind flow disturbance in the area near the roadway wall. As a result, local vortex wind flow was produced, which led to wind flow turbulence in the tunneling end area and reduced the strength of the $1 \#$ air curtain.

For the 2\# air curtain, when the $\gamma$ value was small, the suction volume of the suction tube was much larger than the air volume of the $1 \#$ slit, and a large part of the airflow from the 2\# slit moved toward the tunneling end face, reducing the strength of the 2\# air curtain to block the roadway and weakening the movement of the $2 \#$ air curtain in the direction away from the tunneling end. As the $\gamma$ value increased, the air suction volume gradually decreased, the air volume of the 2\# air curtain flowing toward the tunneling end area decreased, the shielding ability of the 2\# air curtain gradually increased, and the ability of the air curtain to move away from the tunneling end gradually increased.

Figure 8 shows the velocity vector diagram at the $1 \#$ and $2 \#$ slits in the roadway section in parallel with the tunneling end face under different air duct blowing and suction ratios $\gamma$. It can be seen from the figure that under the action of the external arc-shaped wind deflector, a radial air curtain with a good rotating effect was formed in the entire roadway section. Due to the complex environment in the tunnel, the integrity of the $1 \#$ and 2\# air curtains was greatly affected. The 2\# air curtain was approximately in parallel with the tunneling end face, which can be seen more completely in the figure. Since the 1 \# air curtain rushed toward the tunneling end in an umbrella shape, the wind flow of the $1 \#$ air curtain at the $1 \#$ slit was higher at the center of the roadway but lower near the wall of the roadway. When the value of $\gamma$ was smaller, the inclination of the 1 \# air curtain was larger, the central area with larger wind speed on the cross section was smaller, and the low wind speed area was larger. With the increase in the $\gamma$ value, the inclination amplitude of the 1\# air curtain was reduced, and a more obvious wind velocity flow field appeared in the entire roadway section. As the $\gamma$ value increased, the 2\# air curtain had no obvious change. When the value of $\gamma$ was larger, a large wind speed appeared on the wall of the roadway, and the wind flow with a large wind speed blowing vertically to the wall can easily generate turbulence and reduce the anti-interference ability of the air curtain.

4.3. Effect of the Blowing and Suction Air Volume Ratio on Dust Distribution. Figure 9 is a cloud diagram of the 
TABLE 1: Parameter setting of boundary conditions.

\begin{tabular}{|c|c|c|c|c|c|c|}
\hline \multirow[t]{2}{*}{$\begin{array}{l}\text { Blowing and suction } \\
\text { air volume ratio } \gamma\end{array}$} & \multirow[t]{2}{*}{$\begin{array}{l}\text { The air volume of the suction } \\
\text { tube }\left(\mathrm{m}^{3} / \mathrm{min}\right)\end{array}$} & \multirow[t]{2}{*}{$\begin{array}{l}\text { Suction outlet wind } \\
\text { speed }(\mathrm{m} / \mathrm{s})\end{array}$} & \multicolumn{2}{|c|}{$\begin{array}{c}\text { Air volume out of } \\
\text { annular } \\
\text { slit }\left(\mathrm{m}^{3} / \mathrm{min}\right)\end{array}$} & \multicolumn{2}{|c|}{$\begin{array}{c}\text { Outlet wind } \\
\text { speed of annular } \\
\text { slit }(\mathrm{m} / \mathrm{s})\end{array}$} \\
\hline & & & $1 \#$ & 2\# & 3\# & $4 \#$ \\
\hline 1.2 & 250.00 & 14.74 & \multirow{6}{*}{175.00} & \multirow{6}{*}{125.00} & \multirow{6}{*}{12.90} & \multirow{6}{*}{9.22} \\
\hline 1.3 & 230.77 & 13.61 & & & & \\
\hline 1.4 & 214.29 & 12.64 & & & & \\
\hline 1.5 & 200.00 & 11.80 & & & & \\
\hline 1.6 & 187.50 & 11.06 & & & & \\
\hline 1.7 & 176.47 & 10.41 & & & & \\
\hline
\end{tabular}

\begin{tabular}{|ccccc|}
\hline Velocity & 1 &, &, & {$\left[\mathrm{~m} . \mathrm{s}^{\wedge}-1\right]$} \\
0 & 4.5 & 9.0 & 13.5 & 18.0 \\
& $\mathrm{X}(\mathrm{m})$ & & $\mathrm{X}(\mathrm{m})$ &
\end{tabular}
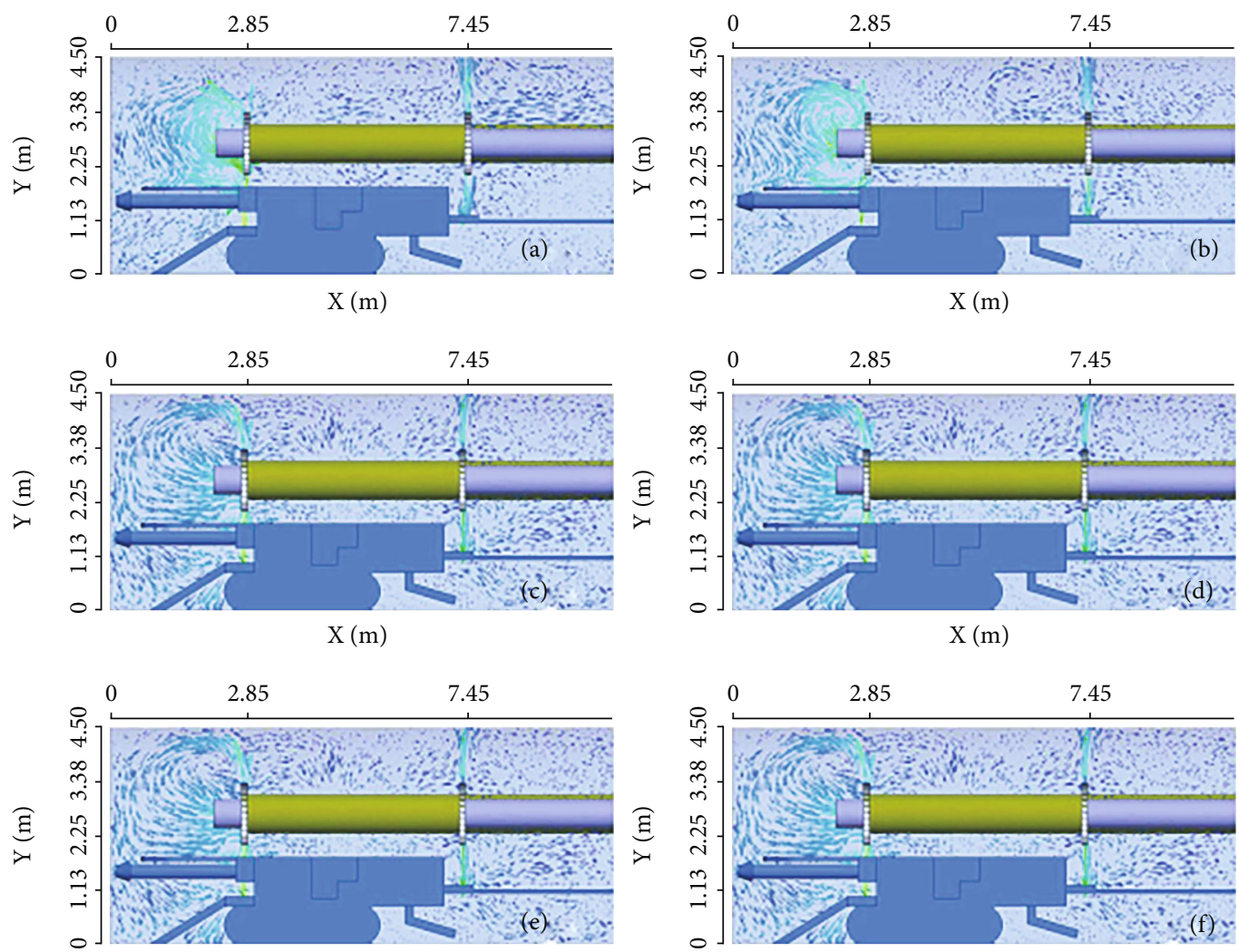

Figure 7: Speed vector diagram of the heading area at the $Z=2.3 \mathrm{~m}$ section: (a) $\gamma=1.2 \mathrm{~mm}$; (b) $\gamma=1.3 \mathrm{~mm}$; (c) $\gamma=1.4 \mathrm{~mm}$; (d) $\gamma=1.5 \mathrm{~mm}$; (e) $\gamma=1.6 \mathrm{~mm}$; (f) $\gamma=1.7 \mathrm{~mm}$.

distribution of dust concentration in the cross section of $Y$ $=1.7 \mathrm{~m}$, which is the height of the breathing zone, under different air duct blowing and suction volume ratios. It can be seen from the figure that as the $\gamma$ value gradually increased, the dust concentration at the driver's position first decreased and then increased and the dust shielding ability of the dual-radial swirl shielding ventilation system first strengthened and then weakened. When the $\gamma$ value was smaller, the negative pressure generated by the large suction volume caused a relatively small wind speed of the 1 \# air curtain at the wall of the roadway, which destroyed the integrity of the $1 \#$ air curtain. As a result, the dust in the tunneling end area broke through the shielding of the 1\# air curtain along the roadway wall and spread to the driver's $\mathrm{cab}$ of the roadheader. Since most of the air volume flowed out to the tunneling end area, the strength of the $2 \#$ air 

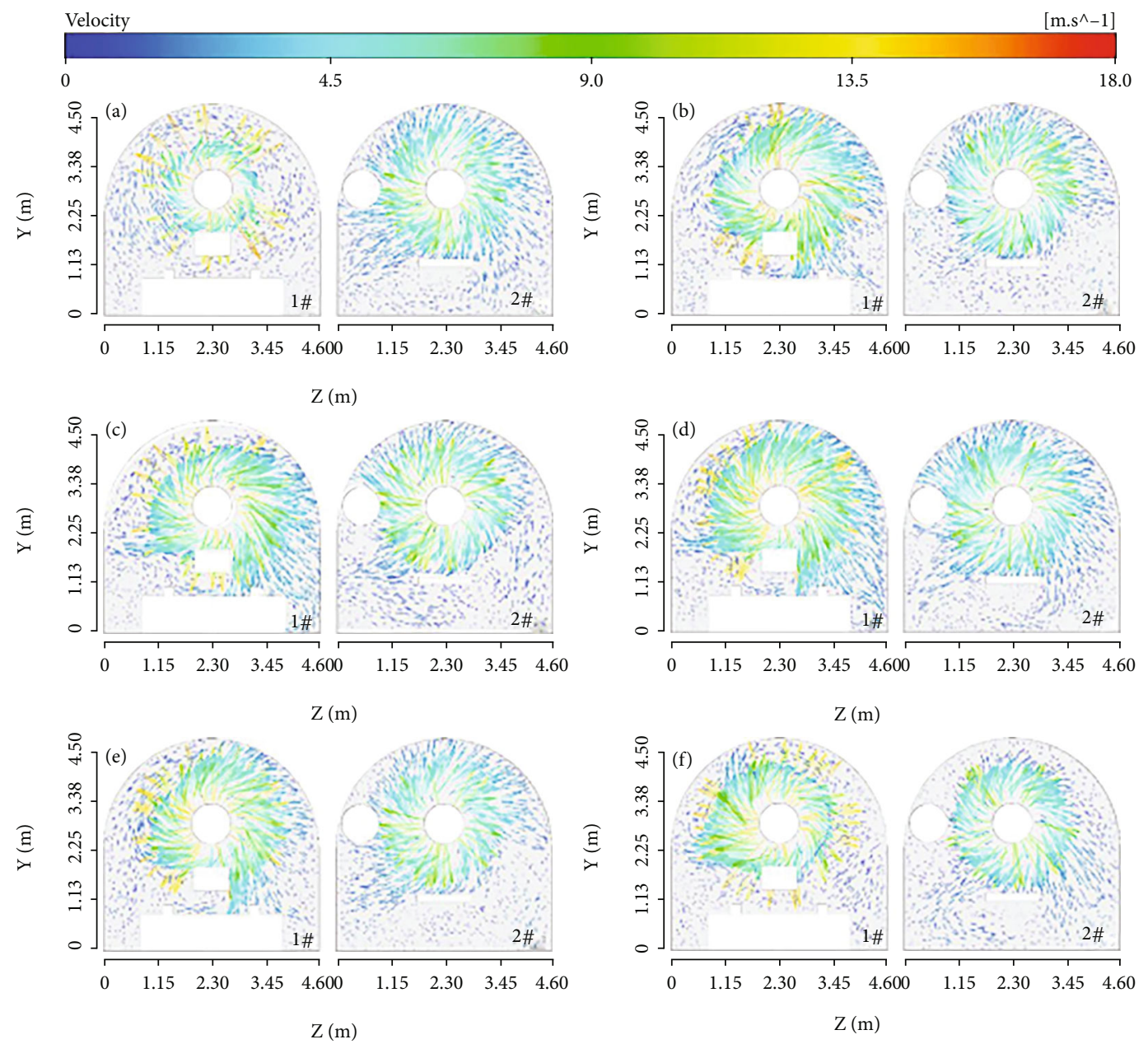

FiguRE 8: Vector diagrams of cross-sectional velocities at $1 \#$ and 2\# slit air vents under different blowing and suction ratios: (a) $\gamma=1.2$; (b) $\gamma=1.3$; (c) $\gamma=1.4$; (d) $\gamma=1.5$; (e) $\gamma=1.6$; (f) $\gamma=1.7$.

curtain moving away from the tunneling end face was insufficient, so a large amount of dust accumulated at the transfer point, which increased the burden of the 2\# air curtain. As a result, the dust control capacity of the $2 \#$ air curtain was seriously inadequate, and the dust at the transfer point spread to the driver's position of the roadheader. As the value of $\gamma$ increased, the dust blocking ability of $1 \#$ and 2\# air curtains gradually increased, the dust diffusion ability of each dust source to the driver's position of the roadheader was weakened, and the dust concentration at the driver's position of the roadheader gradually decreased. When the $\gamma$ value was 1.5 , the air curtain showed the best dust shielding effect. When $\gamma$ continued to increase, the dust control ability of the 1 \# air curtain weakened and the dust control ability of the 2\# air curtain increased. When the $\gamma$ value was too large, large turbulence can be formed near the $1 \#$ air curtain, resulting in the turbulence of the flow field in the tunneling end area. Under this condition, it was difficult for the dust to accumulate. At the same time, due to the reduction of the air suction volume, the dust catching capacity of the suction tube was also reduced, so the dust removal capacity in the tunneling end area was reduced, and the dust concentration increased, which increased the burden of the 1 \# air curtain. As a result, the dust control ability of the 1\# air curtain was weakened, and the dust produced by the tunneling was diffused to the driver's position of the roadheader. Increasing the $\gamma$ value can improve the strength of the 2\# air curtain. Since the total air supply volume was much larger than the suction volume, under the action of the blowing and suction airflow, the 2\# air curtain had a strong ability to move away from the tunneling end, so the dust shielding ability of the $2 \#$ air curtain at the transfer point continued to increase.

Figure 10 shows the variation curve of the dust concentration at the driver's position with the blowing and suction air volume ratio. From Figure 10, as the blowing and suction volume ratio of the air duct increased, the dust concentration at the driver first decreased and then increased. The dust concentration at the driver's position reached the lowest value when the blowing and suction volume ratio $\gamma$ is 1.5 . From the above analysis, it can be concluded that using the dual-radial swirl shielding ventilation in the fully mechanized excavation face, when the blowing and suction air volume ratio was set to 1.5 , the best dust control effect can be obtained. 

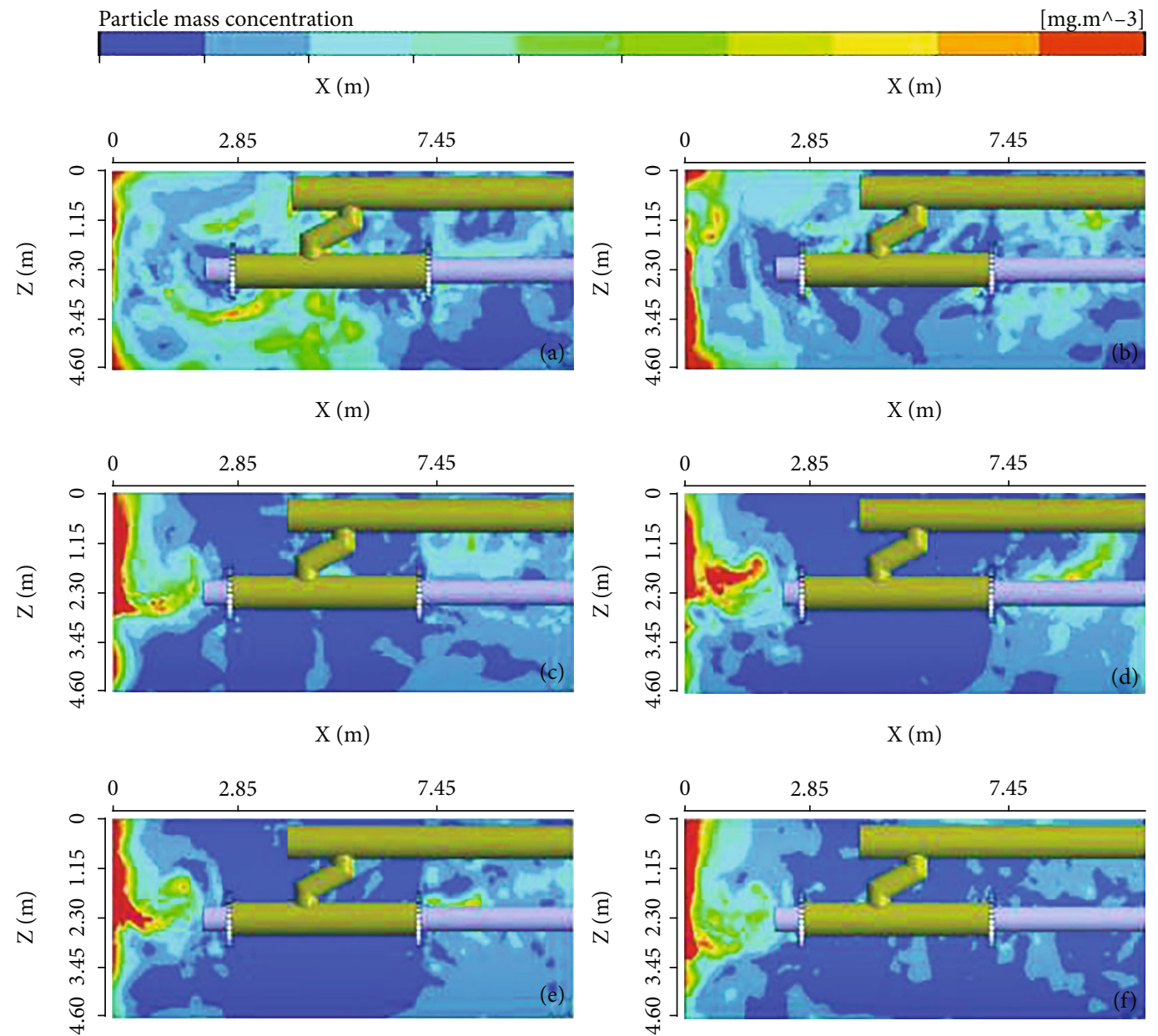

Figure 9: Cloud diagram of dust concentration distribution at the cross section of $Y=1.7 \mathrm{~m}$ under different blowing and suction ratios: (a) $\gamma=1.2$; (b) $\gamma=1.3$; (c) $\gamma=1.4$; (d) $\gamma=1.5$; (e) $\gamma=1.6$; (f) $\gamma=1.7$.

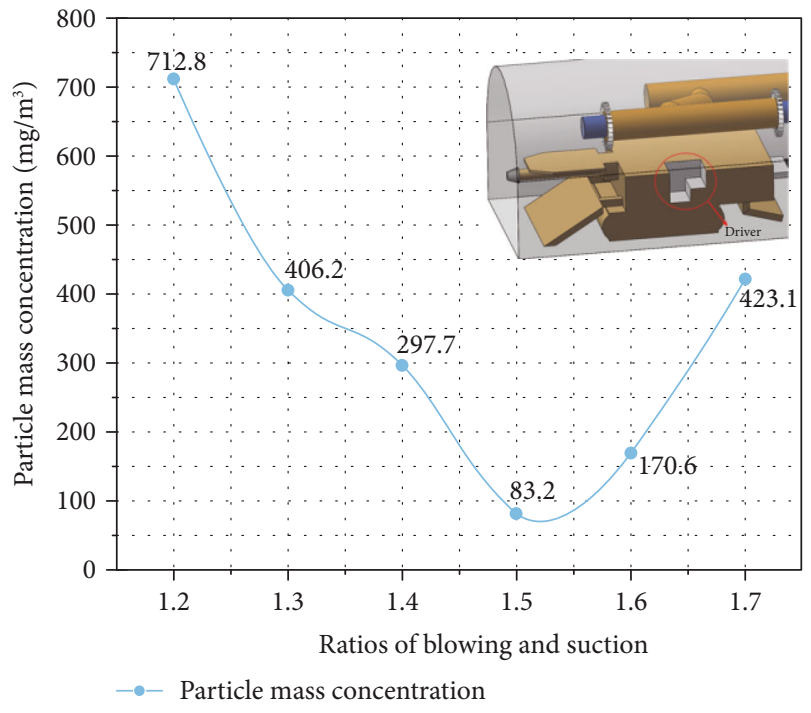

Figure 10: Dust concentration at the driver's position.

\section{Conclusions}

In this study, based on the actual geometric dimensions of the fully mechanized excavation face, the dual-radial swirl shielding ventilation system was modeled using Solidworks software, and the model was numerically simulated by the Fluent software. The validity of the model was verified by a custom-designed experimental model which is geometrically proportional to the real roadway. In the experimental model, the PIV particle image velocimetry system and the FCC-25 explosion-proof dust sampler were used to record the flow field and the dust concentration in the experimental model, respectively. Under the same working conditions with the numerical simulation, the experimental results and numerical simulation results were compared to verify that the numerical model of the dual-radial swirl shielding ventilation system was effective and can be used for more indepth researches on system dust control optimization. From this research, it can be seen that the blowing and suction air volume ratio of the air dust has a significant impact on the dust control effect of the dual-radial swirl shielding ventilation system in the fully mechanized excavation face. A proper setting of the ratio can greatly improve the air 
organization of the dual-radial swirl shielding ventilation system, thereby improving the dust control effect of the system. A too small blowing and suction air volume ratio destroyed the integrity of the $1 \#$ air curtain that was used to block the roadway section. A too large blowing and suction air volume ratio led to gradual turbulence of airflow and local circulating air. Therefore, a too large or too small blowing and suction volume ratio can decrease the dust control capability of the ventilation system. As the blowing and suction volume ratio of the air duct increased, the dust control effect of the dual-radial swirl shielding ventilation system showed a trend of first strengthening and then weakening. When the blowing and suction air volume ratio of the air duct was 1.5, the dust shielding effect was the best.

Due to the limitation of research time and experimental conditions, as well as the complex equipment layout and operation process of the actual fully mechanized mining face, the research results need to be further tested on-site.

\section{Data Availability}

Data sharing is not applicable to this article as no datasets were generated or analyzed during the current study.

\section{Conflicts of Interest}

The authors declare that they have no conflicts of interest.

\section{Acknowledgments}

This research was financially supported by the National Natural Science Foundation of China (51774135, 51974120), the Hunan Postgraduate Research and Innovation Funding Project (CX2018B657), and the Open Fund Project of Southern Coal Mine Gas and Roof Disaster Prevention and Control Work Safety Key Laboratory (E21825).

\section{References}

[1] Y. H. Liu, W. Nie, Y. B. Mu et al., "A synthesis and performance evaluation of a highly efficient ecological dust depressor based on the sodium lignosulfonate-acrylic acid graft copolymer," RSC Advances, vol. 8, no. 21, pp. 11498-11508, 2018.

[2] S. Yin, W. Nie, L. Guo et al., "CFD simulations of air curtain dust removal effect by ventilation parameters during tunneling," Advanced Powder Technology, vol. 31, no. 6, pp. 24562468, 2020.

[3] B. Tan, H. Liu, B. Xu, and T. Wang, "Comparative study of the explosion pressure characteristics of micro- and nano-sized coal dust and methane-coal dust mixtures in a pipe," International Journal of Coal Science \& Technology, vol. 7, no. 1, pp. 68-78, 2020.

[4] P. F. Wang, X. H. Tan, W. M. Cheng, G. Guo, and R. H. Liu, "Dust removal efficiency of high pressure atomization in underground coal mine, International Journal of Mining Science and Technology," vol. 28, no. 4, pp. 685-690, 2018.

[5] P. F. Wang, K. Zhang, and R. H. Liu, "Influence of air supply pressure on atomization characteristics and dust-suppression efficiency of internal-mixing air-assisted atomizing nozzle," Powder Technology, vol. 355, pp. 393-407, 2019.
[6] Y. J. Li, P. F. Wang, R. H. Liu, Y. D. Jiang, and H. Han, “Determination of the optimal axial-to-radial flow ratio of the wallmounted swirling ventilation in fully mechanized excavation face," Powder Technology, vol. 360, pp. 890-910, 2020.

[7] Q. Bao, W. Nie, C. Q. Liu et al., "The preparation of a novel hydrogel based on crosslinked polymers for suppressing coal dusts," Journal of Cleaner Production, vol. 294, p. 1193, 2019.

[8] P. F. Wang, Y. J. Shi, L. Y. Zhang, and Y. J. Li, "Effect of structural parameters on atomization characteristics and dust reduction performance of internal-mixing air-assisted atomizer nozzle," Process Safety and Environmental Protection, vol. 128, pp. 316-328, 2019.

[9] H. Han, P. F. Wang, Y. J. Li, R. H. Liu, and C. Tian, "Effect of water supply pressure on atomization characteristics and dustreduction efficiency of internal mixing air atomizing nozzle," Advanced Powder Technology., vol. 31, no. 1, pp. 252-268, 2020.

[10] Q. Liu, W. Nie, Y. Hua, H. T. Peng, and Z. Q. Liu, “The effects of the installation position of a multi-radial swirling air- curtain generator on dust diffusion and pollution rules in a fully-mechanized excavation face: a case study," Powder Technology, vol. 329, pp. 371-385, 2018.

[11] P. F. Wang, R. Z. Gao, R. H. Liu, and F. Q. Yang, "CFDbased optimization of the installation location of the wallmounted air duct in a fully mechanized excavation face," Process Safety and Environmental Protection, vol. 141, pp. 234-245, 2020.

[12] S. Akhshik, M. Behzad, and M. Rajabi, "CFD-DEM approach to investigate the effect of drill pipe rotation on cuttings transport behavior," Journal of Petroleum Science and Engineering, vol. 127, pp. 229-244, 2015.

[13] D. W. Chen, W. Nie, P. Cai, and Z. Q. Liu, "The diffusion of dust in a fully-mechanized mining face with a mining height of $7 \mathrm{~m}$ and the application of wet dust-collecting nets,"Journal of Cleaner Production, vol. 205, pp. 463-476, 2018.

[14] Z. A. Jiang, "Study on similarity of gas-solid two-phase flow in ventilation and dust removal," Coal Engineer, vol. 40, pp. 1215, 1993.

[15] F. Camelli, G. Byrne, and R. Löhner, "Modeling subway air flow using CFD," Tunneling and Underground Space Technology, vol. 43, pp. 20-31, 2014.

[16] Z. A. Jiang, P. Yan, J. S. Chen, and Z. Y. Zhang, "Optimization on parameters of long distance forced and short distance exhausted ventilation system in mine rock heading roadway," Coal Science and Technology, vol. 43, pp. 54-58, 2019.

[17] S. Y. Hu, Q. Liao, G. R. Feng et al., "Numerical study of gassolid two-phase flow around road-header drivers in a fully mechanized excavation face," Powder Technology, vol. 344, pp. 959-969, 2019.

[18] Z. Korecki and W. Skoczynski, "KOMAG mining mechanization center-service to the cause of mining from 1945-1985," Mechanizacja Automatyzacja Gornictwa, vol. 24, pp. 12-26, 1986.

[19] C. Q. Liu, W. Nie, Q. Bao, Q. Liu, C. H. Wei, and Y. Hua, "The effects of the pressure outlet's position on the diffusion and pollution of dust in tunnel using a shield tunneling machine," Energy \& Buildings, vol. 176, pp. 232-245, 2018.

[20] W. Nie, W. L. Wei, P. Cai et al., "Simulation experiments on the controllability of dust diffusion by means of multi-radial vortex airflow," Advanced Powder Technology, vol. 29, no. 3, pp. 835-847, 2018. 
[21] X. F. Ren, X. M. Hu, D. Xue et al., "Novel sodium silicate/polymer composite gels for the prevention of spontaneous combustion of coal," Journal of Hazardous Materials, vol. 371, pp. 643-654, 2019.

[22] Z. Q. Liu, W. Nie, H. T. Peng, S. B. Yang, D. W. Chen, and Q. Liu, "The effects of the spraying pressure and nozzle orifice diameter on the atomizing rules and dust suppression performances of an external spraying system in a fully-mechanized excavation face," Powder Technology, vol. 350, pp. 62-80, 2019.

[23] J. P. Minier, "On Lagrangian stochastic methods for turbulent polydisperse two-phase reactive flows," Progress in Energy and Combustion Science, vol. 50, pp. 1-62, 2015.

[24] W. Nie, W. L. Wei, X. Ma, Y. H. Liu, H. T. Peng, and Q. Liu, "The effects of ventilation parameters on the migration behaviors of head-on dusts in the heading face," Tunnelling and Underground Space Technology, vol. 70, pp. 400-408, 2017.

[25] Q. Zhou, B. T. Qin, F. Wang, H. T. Wang, J. Hou, and Z. R. Wang, "Effects of droplet formation patterns on the atomization characteristics of a dust removal spray in a coal cutter," Powder Technology, vol. 344, pp. 570-580, 2019.

[26] Y. J. Shi, P. F. Wang, R. H. Liu, X. H. Tan, and W. Zhang, "Numerical simulation and engineering application of coalbed water injection," Mathematical Problems in Engineering, vol. 2019, Article ID 6309160, 12 pages, 2019.

[27] P. F. Wang, Y. J. Li, R. H. Liu, and Y. J. Shi, "Effects of forcedto-exhaust ratio of air volume on dust control of wall- attached swirling ventilation for mechanized excavation face," Tunnelling and Underground Space Technology., vol. 90, pp. 194207, 2019.

[28] C. Tan, Z. A. Jiang, M. Wang, and Y. Chen, "Similarity experiment on multi-source dust diffusion law in fully mechanized caving face," China National Coal Association, vol. 40, pp. 122-127, 2015.

[29] Q. Zhou, B. T. Qin, F. Wang, and H. T. Wang, "Experimental investigation on the performance of a novel magnetized apparatus used to improve the dust suppression ability of surfactant-magnetized water," Powder Technology, vol. 354, pp. 149-157, 2019.

[30] W. J. Yin, G. Zhou, and D. H. Gao, "Simulation analysis and engineering application of distribution characteristics about multi-stage atomization field for cutting dust in fully mechanized mining face," Advanced Powder Technology, vol. 30, no. 11, pp. 2600-2615, 2019.

[31] S. Yin, W. Nie, Q. Liu, and Y. Hua, "Transient CFD modelling of space-time evolution of dust pollutants and air- curtain generator position during tunneling," Journal of Cleaner Production, vol. 239, article 117924, 2019.

[32] B. Sun, W. M. Cheng, J. Y. Wang, and H. Wang, "Effects of turbulent airflow from coal cutting on pollution characteristics of coal dust in fully-mechanized mining face: a case study," Journal of Cleaner Production, vol. 201, pp. 308-324, 2018. 